\title{
STUDENTS ASSESSING GEOLOGIC HAZARDS USING ONLINE TOOLS
}

\author{
Kyle Gray \\ Dept. of Earth and Environmental Sciences \\ University of Northern lowa
}


"The geologist... may consider it good luck if he can glimpse a rock exposure once or twice a day."

$$
\text { -David Dale Owen (1852) }
$$

Describing field mapping in lowa 


\section{Challenge Teaching Geology in Midwest}

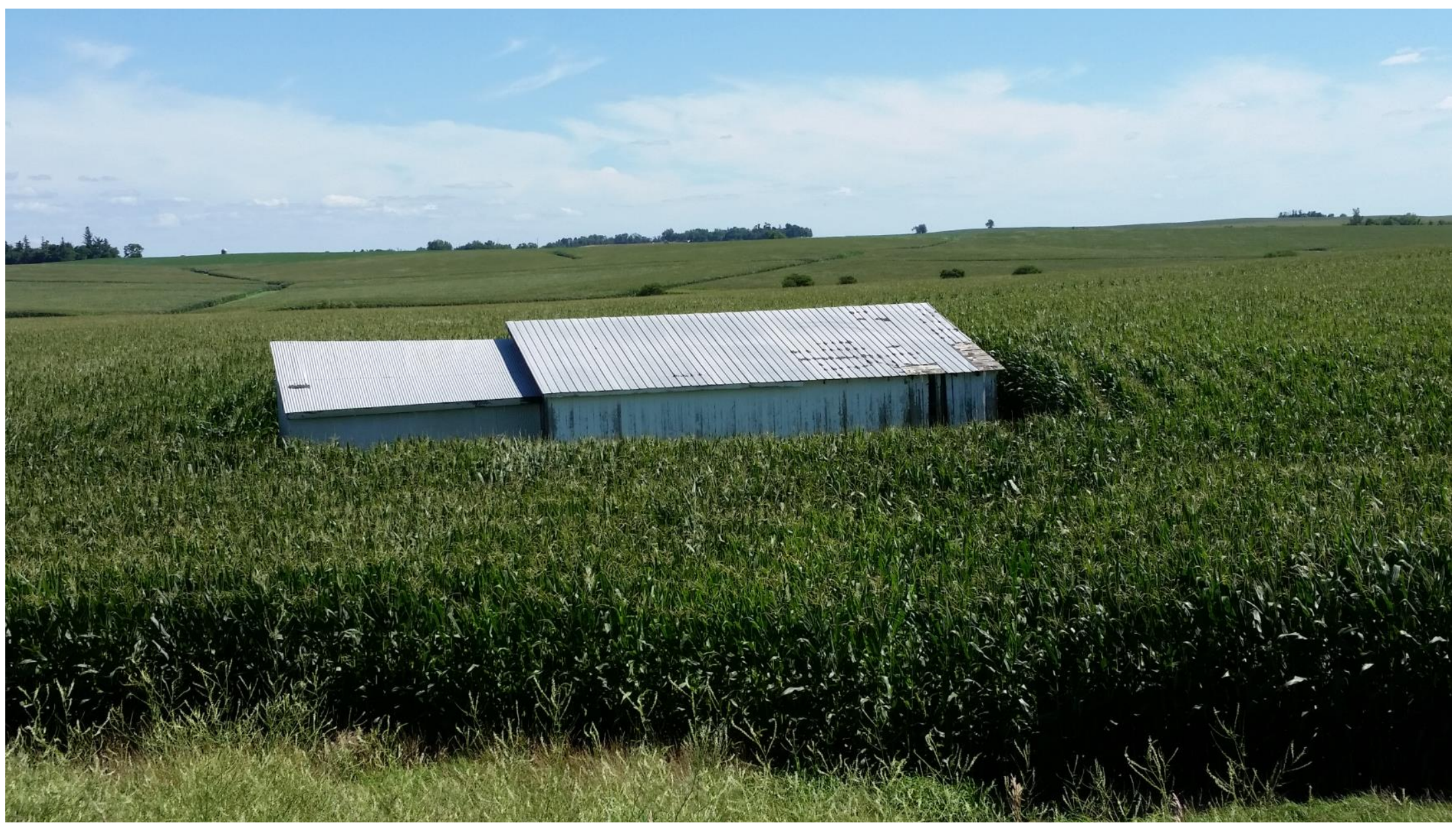




\section{Challenge Teaching Geology in Midwest}
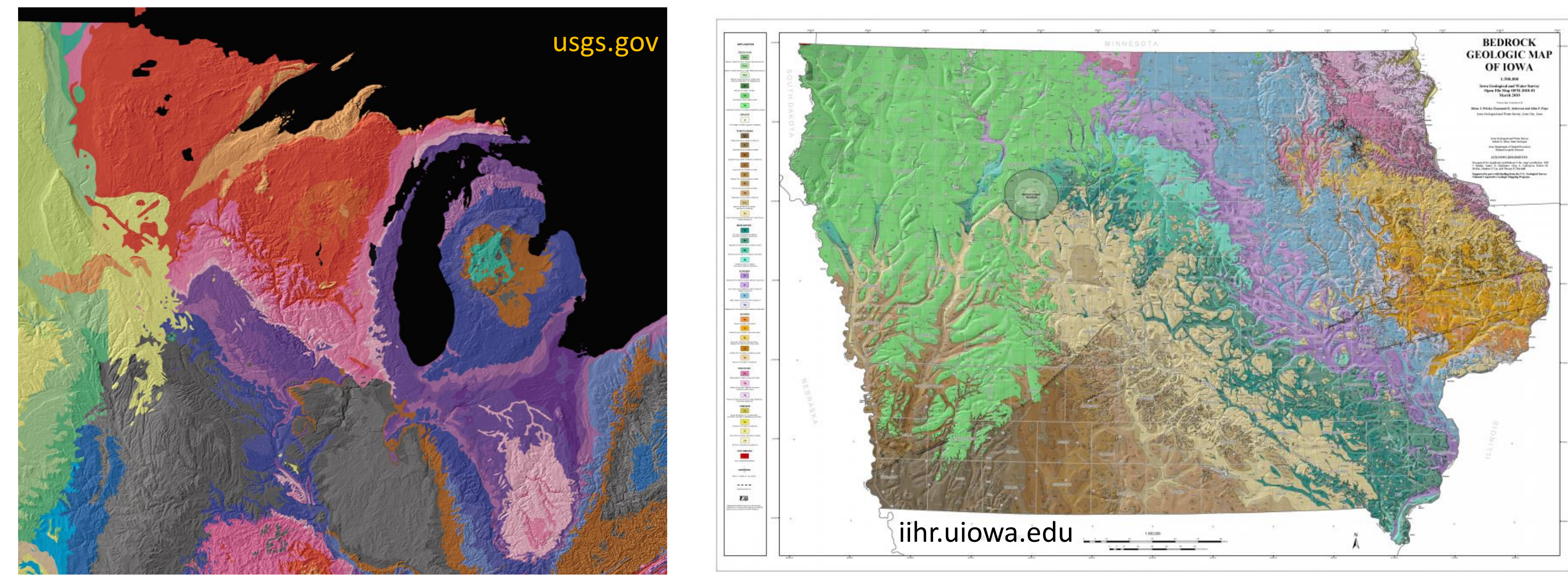


\section{Online Geoscience Resources}

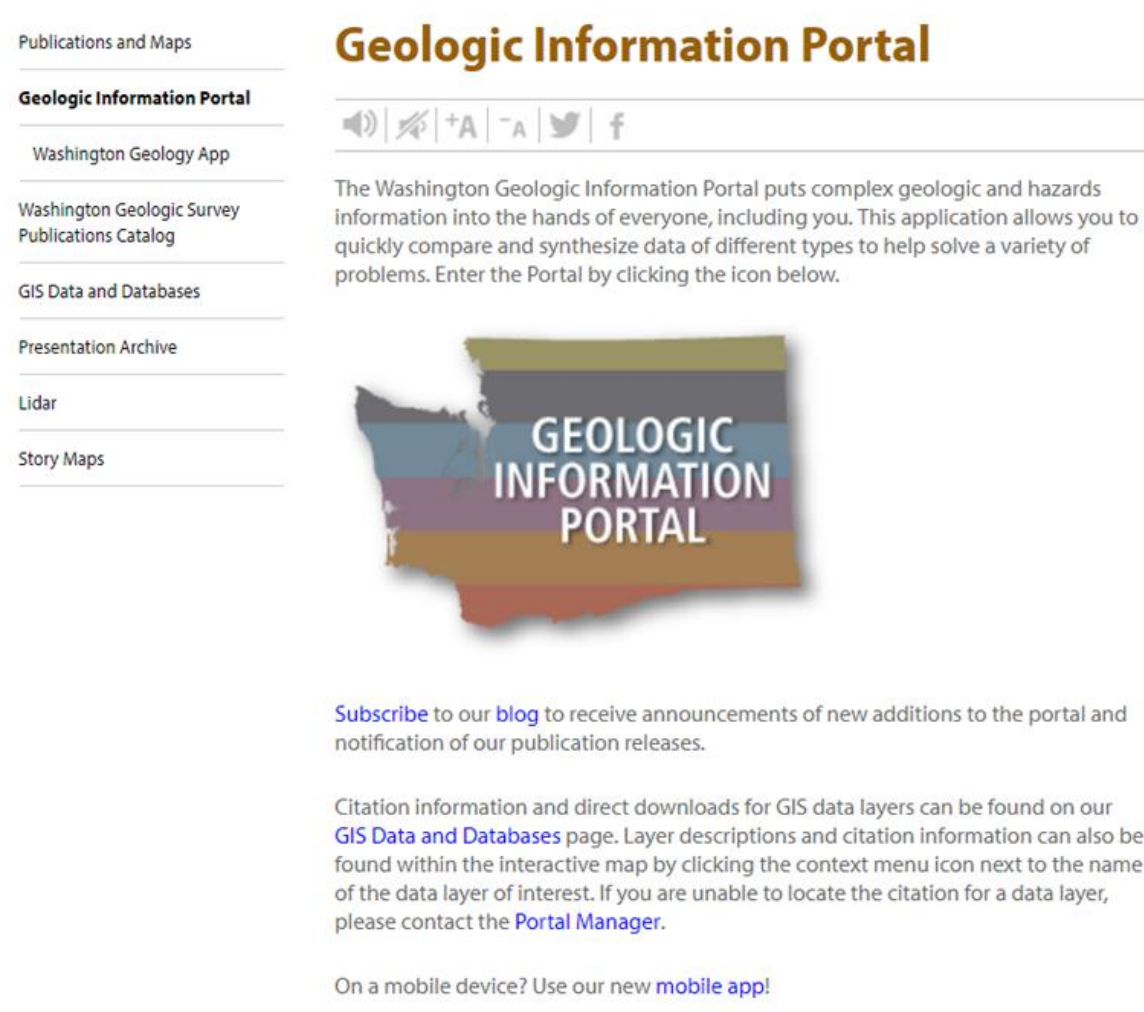

HELP USING THE INTERACTIVE PORTAL

Visit our Portal Help for information about portal navigation and tools

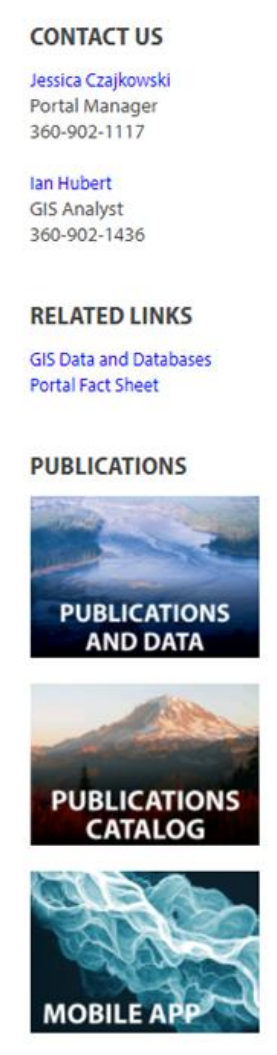

Interactive Maps
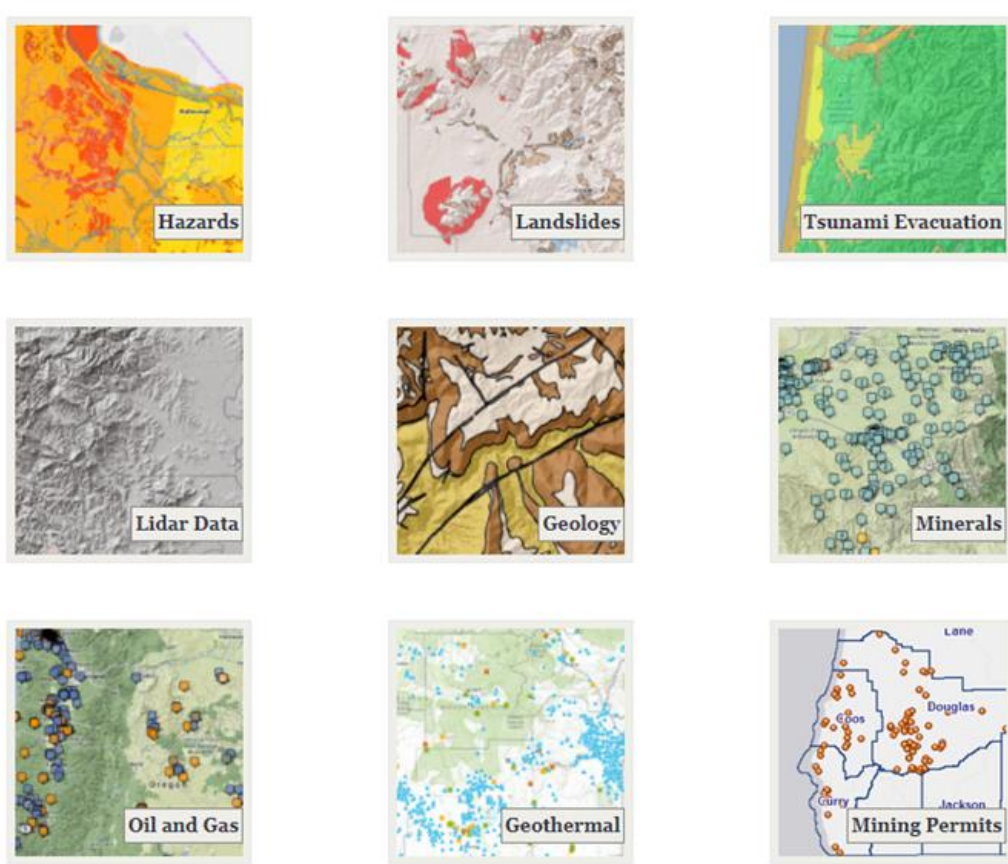

www.dnr.wa.gov/geologyportal

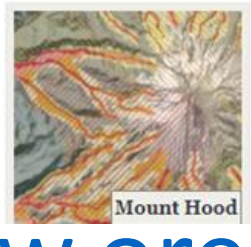




\section{Hazards Project - Selected Cities}

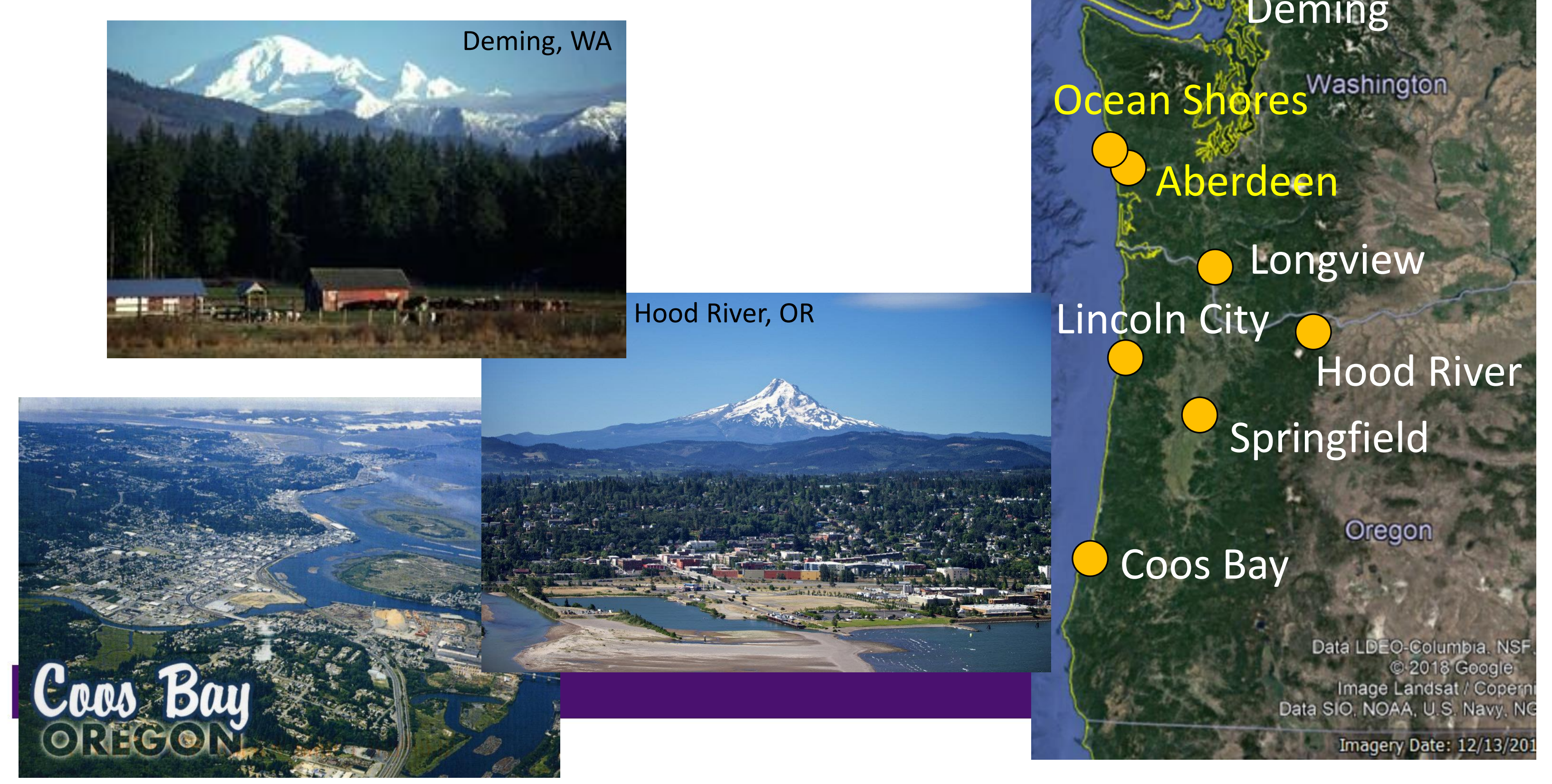




\section{Hazards Project - Assigned Tasks}

-3-4 Students per Group

- Tasks:

- Describe Geography/Geology

- Assess all hazards

- Identify \#1 Need

- Propose a solution

- Products

- Group oral presentation

- Individual Papers

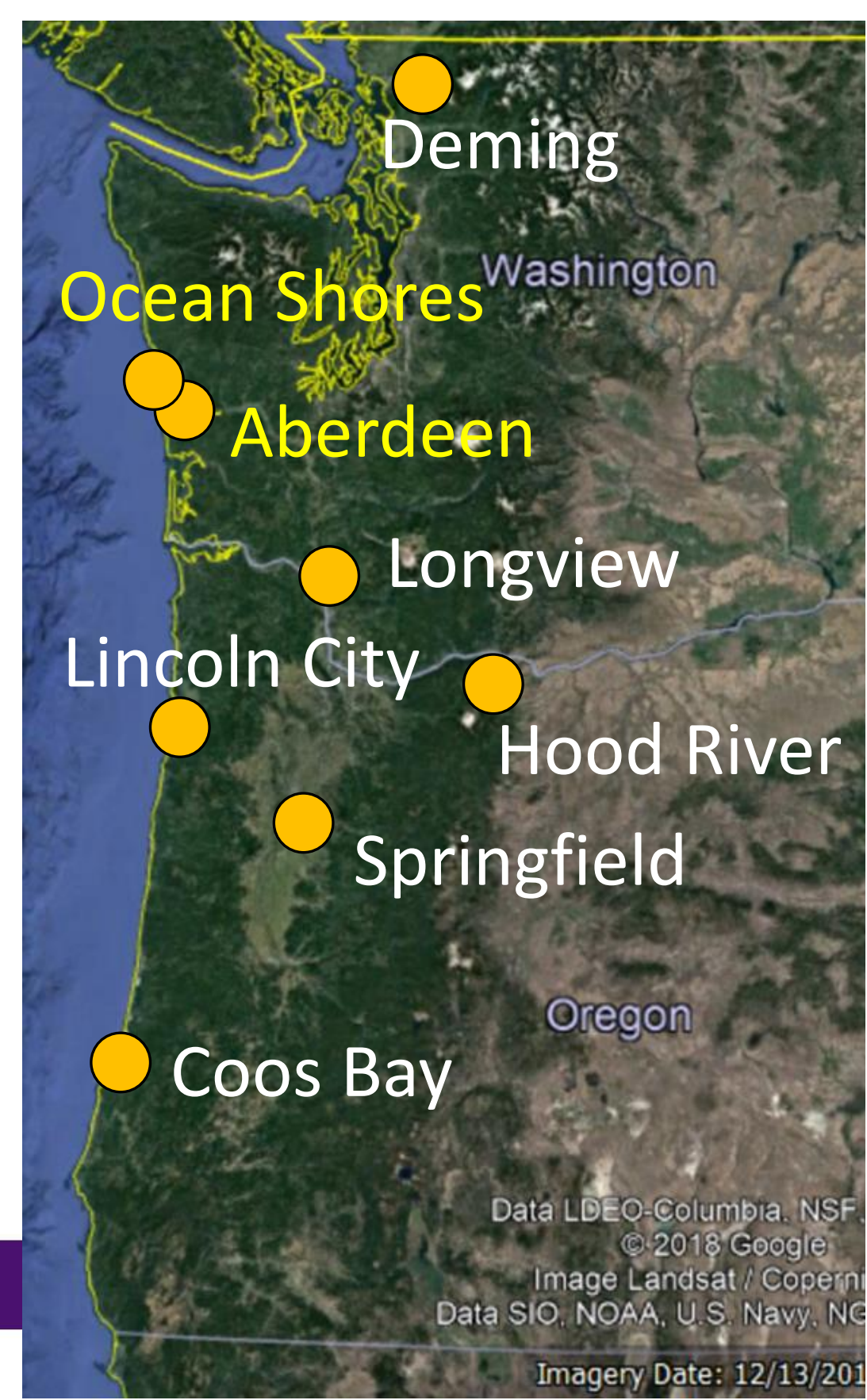




\section{Hazards Project - Hazards Assessed}

- Bedrock Geology

- Seismic Hazards

- Shaking

- Liquefaction

- Tsunami

- Public Building Safety

- Volcanic Hazards

- Landslides

- Coastal Erosion (Oregon)

- Floods (FEMA)

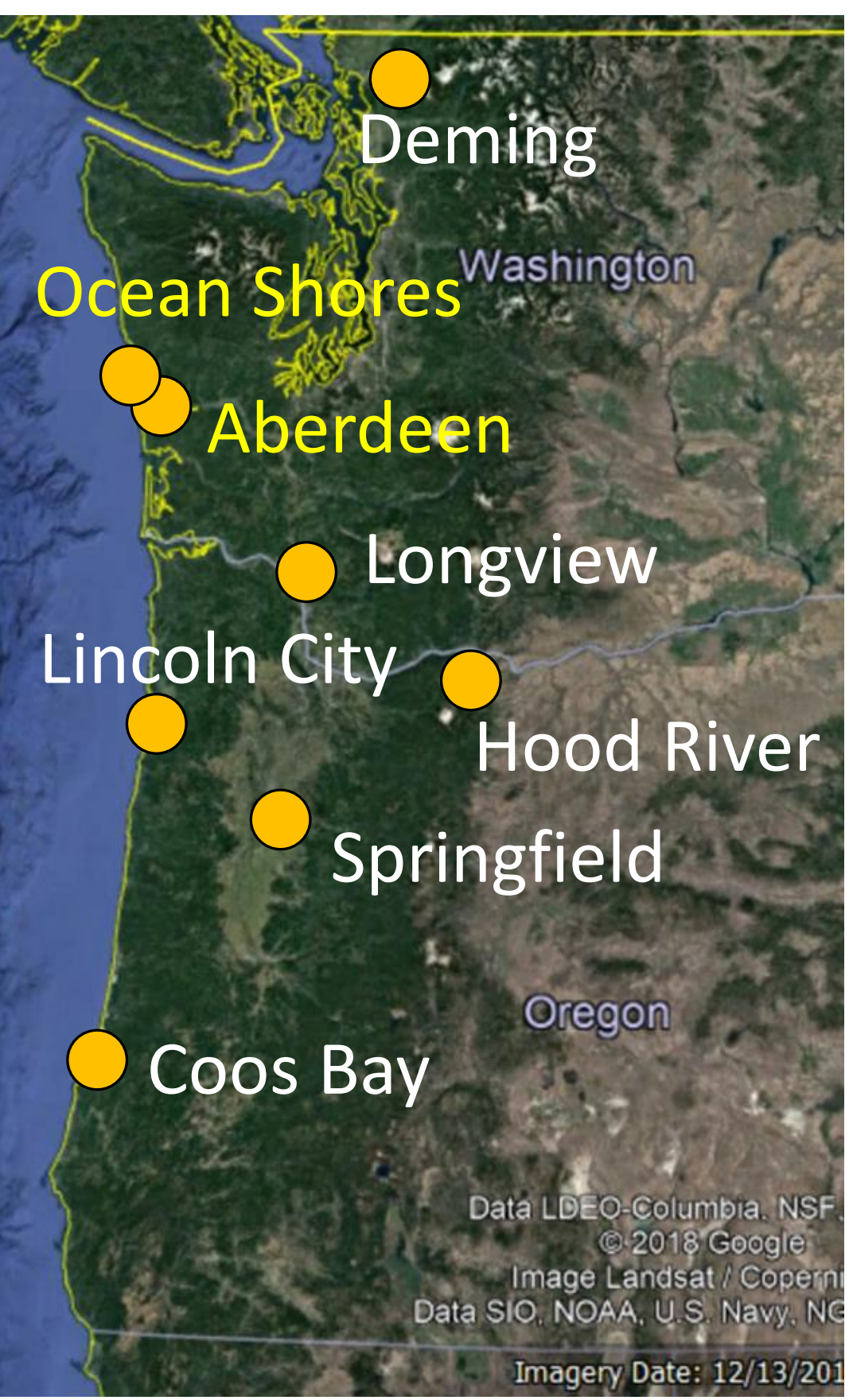




\section{Grays Harbor}

Population

- County $=72,697$

1 Hospital

- 140 Beds

13 Fire Stations

22 Schools
Ocean Shores

cean Shores
Aberdeen

Hoquiam 


\section{Your Task}

- Review Hazards (Maps)

- Biggest Risk

- 1 Solution

Ocean Shores

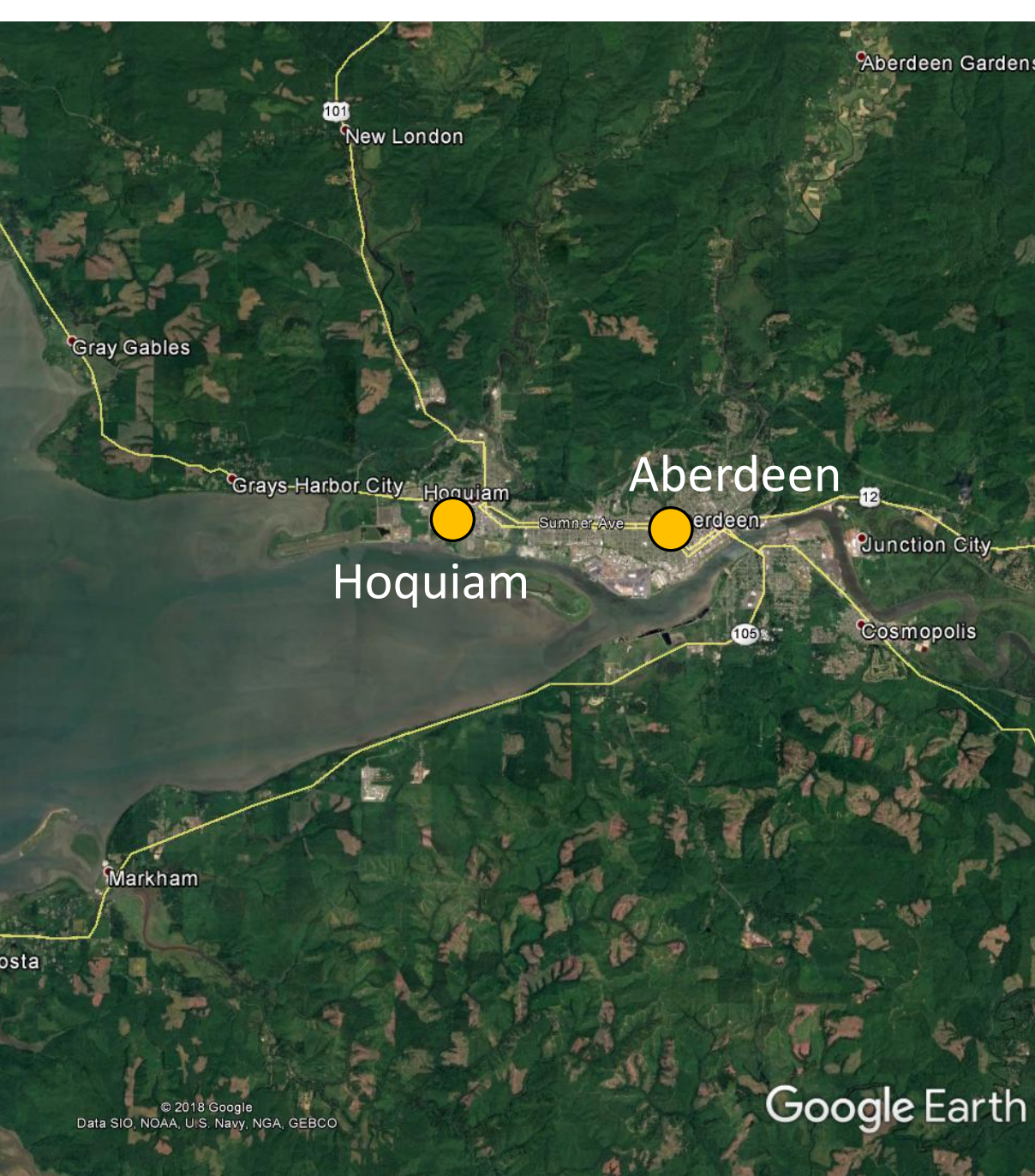




\section{Bedrock Geology}

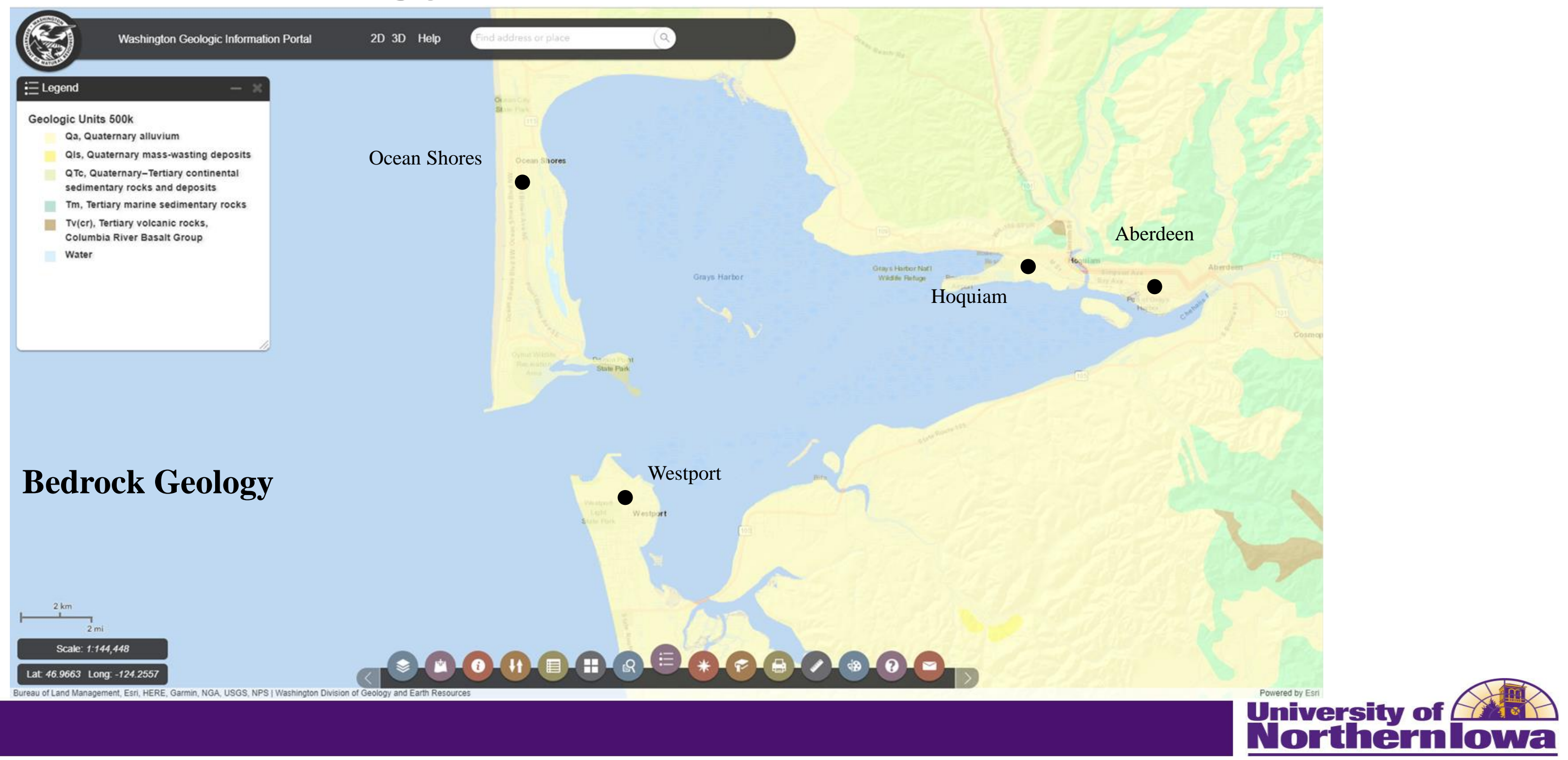




\section{Predicted Shaking - 9.0 Cascadia Quake}

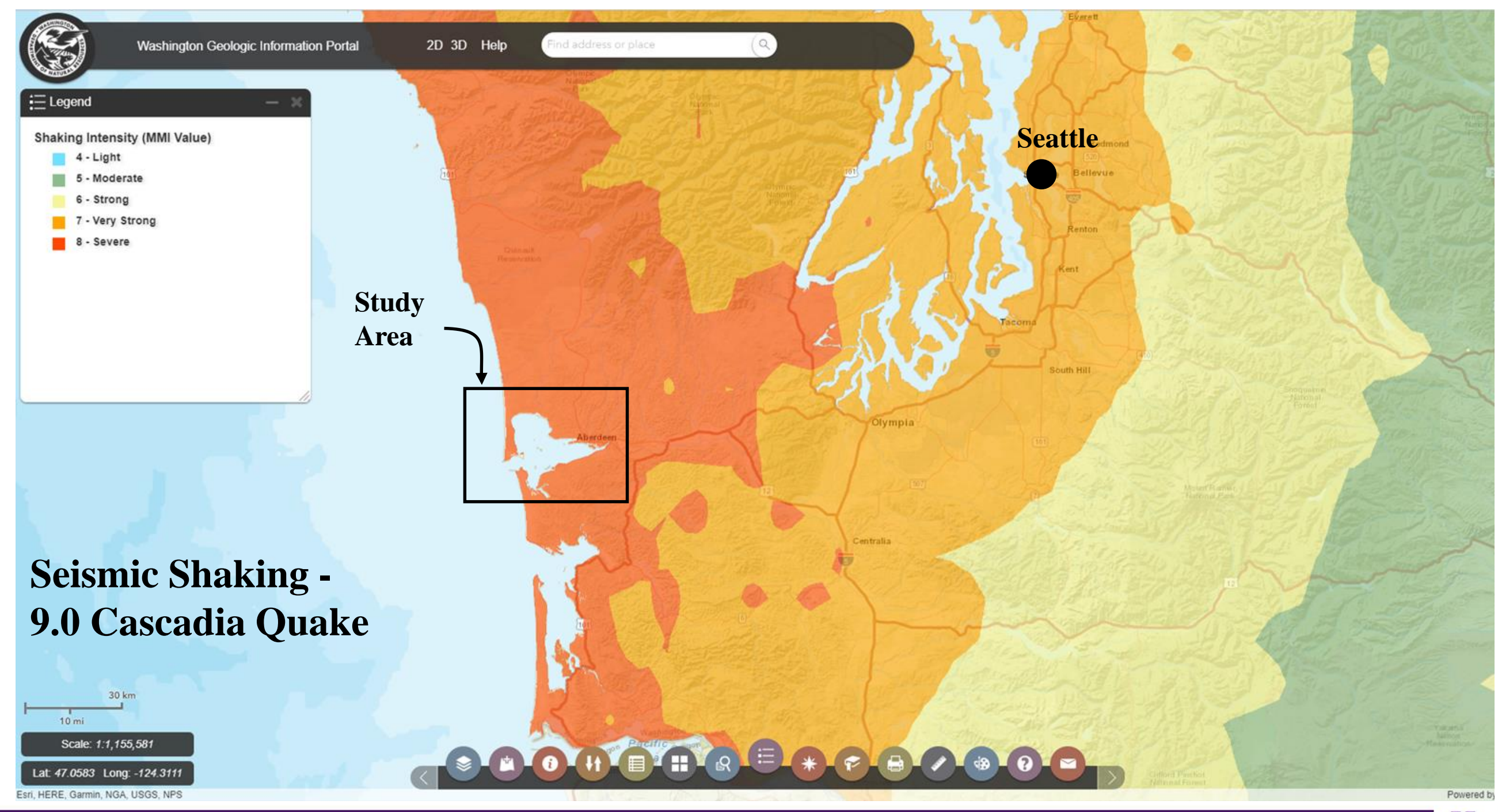




\section{Liquefaction Hazards}

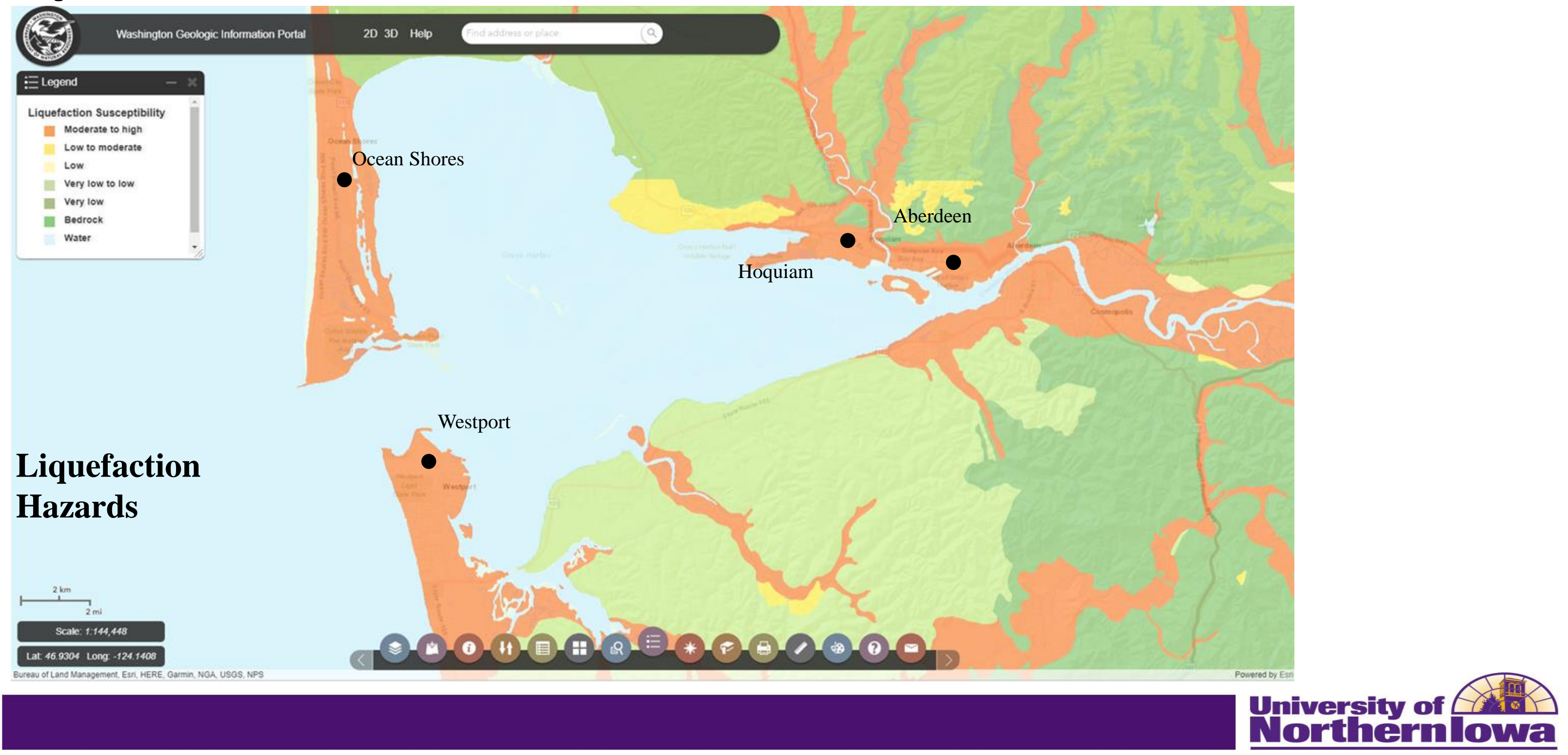




\section{Liquefaction Hazards}

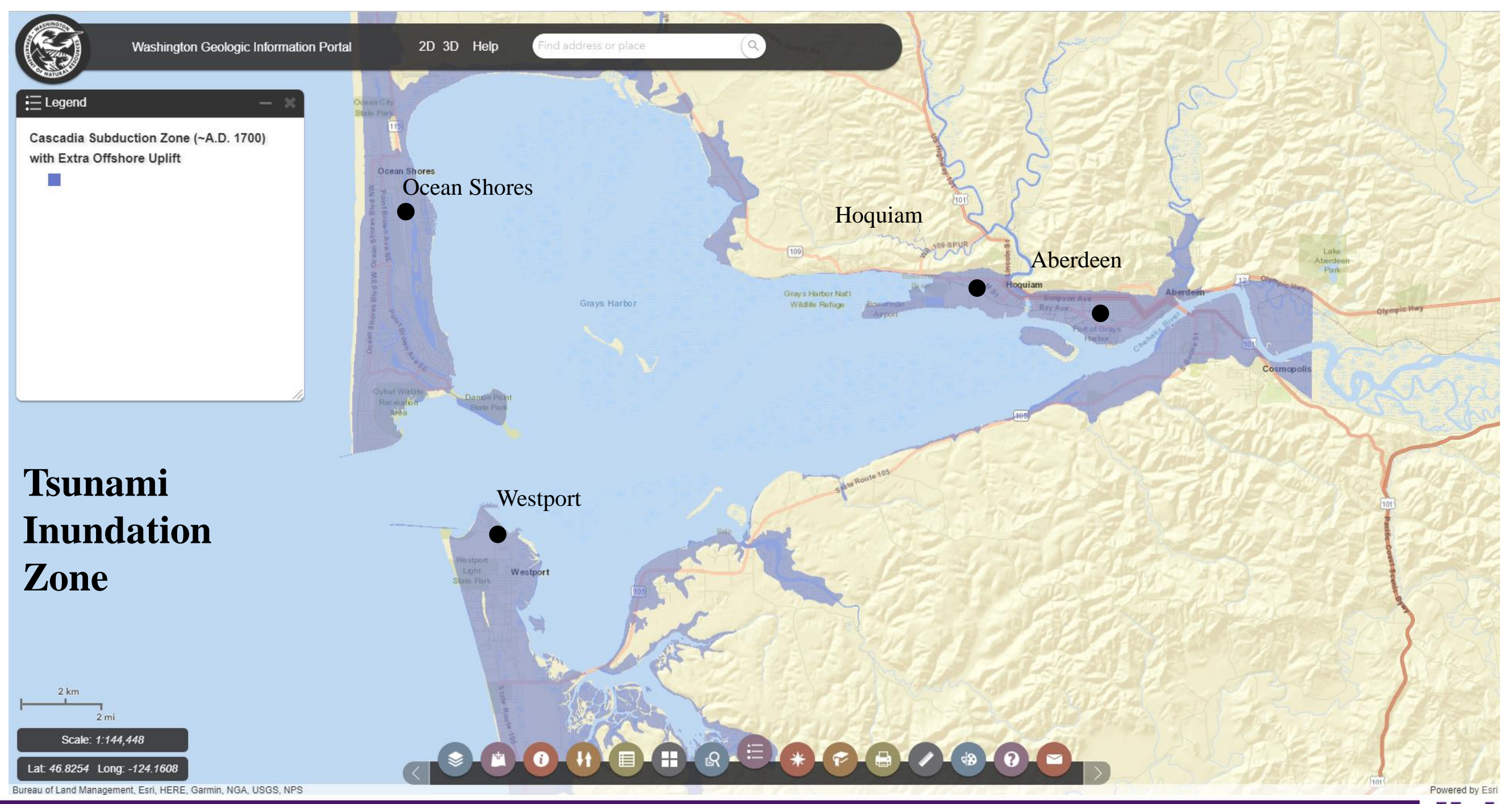




\section{Ocosta Elementary}

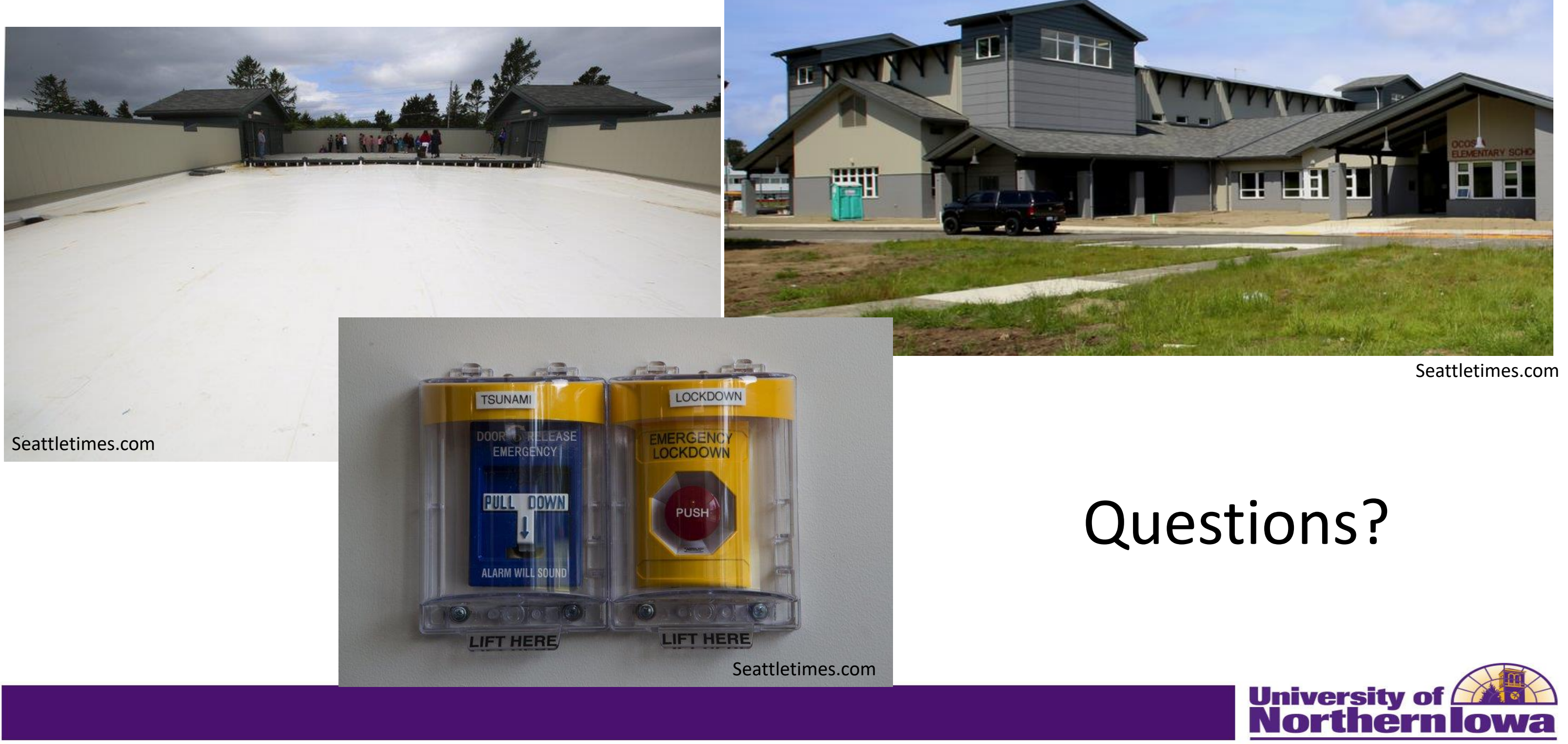

